Check for updates

Cite this: RSC Adv., 2018, 8, 19701

\title{
A highly selective TPE-based AIE fluorescent probe is developed for the detection of $\mathrm{Ag}^{+} \dagger$
}

\author{
Zhixiang Lu, Yunming Liu, Shuhan Lu, Yuan Li, Xiaolan Liu, Yu Qin and Liyan Zheng (D) * \\ The detection of $\mathrm{Ag}^{+}$in the environment is very important to determine the level of pollution from silver \\ complexes, which have caused various human health problems. Herein, an aggregation-induced \\ emission (AIE) chromophore (tetraphenylethane, TPE) attached to a benzimidazole group (tetra- \\ benzimidazole, TBI-TPE) is synthesized and utilized to detect $\mathrm{Ag}^{+}$in the environment. The strong \\ chelating effect between the benzimidazole group and $\mathrm{Ag}^{+}$leads to the formation of aggregates, and \\ strong yellow fluorescence signals were observed after adding $\mathrm{Ag}^{+}$into a TBI-TPE solution. The \\ stoichiometry of the complex of TBI-TPE and $\mathrm{Ag}^{+}$was established to be $1: 2$ using photochemical and \\ mass spectra measurements. The detection limit of the $\mathrm{Ag}^{+}$assay is $90 \mathrm{nM}$ with a linear range from \\ $100 \mathrm{nM}$ to $6 \mu \mathrm{M}$. This study provides a facile method to determine $\mathrm{Ag}^{+}$in real environmental samples \\ with satisfactory results.
}

Received 26th April 2018 Accepted 22nd May 2018

DOI: 10.1039/c8ra03591a

rsc.li/rsc-advances

$\mathrm{Ag}^{+}$detection are based on quenching effects due to a charge

\section{Introduction}

Silver is an important basic metal and has many applications, including pharmaceuticals, the chemical industry, accessories, electronics, photography and so on. ${ }^{\mathbf{1 - 4}}$ Metal pollution resulting from industrial processes including leather tanning, cement production, and metal plating is a serious environmental problem. ${ }^{5-8}$ In the pharmaceutical industry low concentrations of silver complexes are used for their strong antibacterial effect. However, at high concentrations silver is harmful to human health and can cause brain damage, skin oxidation and have negative impacts on the immune system. ${ }^{9-13}$ So it is imperative to establish a highly selective and sensitive method for detecting $\mathrm{Ag}^{+}$in the environment.

Conventional methods for the detection of $\mathrm{Ag}^{+}$include atomic absorption spectrometry, atomic emission spectrometry, potentiometric titration, inductively coupled plasma-mass spectrometry (ICP-MS), electrochemistry, molecular imprinting biosensors and colorimetry etc. ${ }^{\mathbf{1 4 - 2 0}}$ Although these methods can be used to detect lower concentrations of $\mathrm{Ag}^{+}$, they require complex instrumentation, tedious operations and timeconsuming sample pretreatment. Compared to these methods, fluorescence spectroscopy has many advantages, such as low cost, high sensitivity, easy operation and simple sample preparation..$^{\mathbf{2 0 - 2 4}}$ Nevertheless, it is well known that $\mathrm{Ag}^{+}$is commonly used as a fluorescent quencher, and most reports on

Key Laboratory of Medicinal Chemistry for Natural Resource, Ministry of Education, Functional Molecules Analysis and Biotransformation Key Laboratory of Universities in Yunnan Province, School of Chemical Science and Technology, Yunnan University, Kunming, Yunnan 650091, China.E-mail: zhengliyan@ynu.edu.cn

$\dagger$ Electronic supplementary information (ESI) available. See DOI: 10.1039/c8ra03591a transfer process between $\mathrm{Ag}^{+}$and a probe. Fluorescent probes for $\mathrm{Ag}^{+}$with "turn on" type signals are rarely reported. ${ }^{25-30}$

The emergence of aggregation-induced emission (AIE) fluorophores have provided many chances to build "signal on" probes, where fluorescence is weak when dissolved, but becomes significantly more emissive in the aggregate state. Restriction of intramolecular rotation is the main AIE mechanism, in which the intramolecular rotations are greatly hampered due to limited space when aggregated. The nonradiation decay channels are inhibited, and the excited states can only go back to the ground state by radiation decay, thus enhancing the fluorescence significantly. ${ }^{31-36}$ In recent years, fluorescent materials with AIE properties have drawn extensive attention because they have a wide range of applications in many fields, including fluorescent cell imaging, organic lightemitting diodes, sensor materials, protein conformation studies, chiral recognition and so on. ${ }^{37-46}$ Among these AIE molecules, TPE is one of the most widely studied and used materials owing to its excellent optical properties, high quantum yield and photostability. ${ }^{47-51}$

It has been reported that $\mathrm{Ag}(\mathrm{I})$ possesses high affinity for benzimidazole leading to stable coordination complexes. ${ }^{51-57}$ With these considerations in mind, we designed and synthesized a novel fluorophore containing TPE and a benzimidazole group for the first time. The TBI-TPE is rich in $\mathrm{N}$ atoms, which offers good coupling ability with $\mathrm{Ag}^{+}$. Based on the strong coordination, $\mathrm{Ag}^{+}$and TBI-TPE formed an AIE aggregate inducing significant fluorescence enhancement, hence a new fluorescence "turn on" sensor for the detection of $\mathrm{Ag}^{+}$is developed. This AIE probe exhibits high chemical selectivity and 
a fast response time and has been successfully utilized in the determination of $\mathrm{Ag}^{+}$in real environmental samples.

\section{Experimental section}

\subsection{Materials}

4,4'-Dimethylbenzophenone, titanium tetrachloride $\left(\mathrm{TiCl}_{4}\right)$, pyridine, $N$-bromobutanimide (NBS), dibenzoyl peroxide (BPO), and 1,2-diaminobenzene were purchased from Aladdin. Anhydrous tetrahydrofuran, silver nitrate, sodium acetate trihydrate, and chloroform- $d$, 99.8 atom\% D were purchased from Energy Chemical. Dimethyl sulfoxide- $d_{6}$ was purchased from SigmaAldrich. All other reagents were of analytical grade and used as received. Ultrapure water was prepared using a Milli-Q water purification system.

\subsection{Apparatus}

Fluorescence spectra were recorded on a Hitachi HighTechnologies Corporation Tokyo Japan 5J2-0004 model F-7000 FL spectrofluorometer. UV-vis absorption was characterized by a UV-vis/NIR spectrophotometer (Shimadzu, Japan). The NMR spectra were recorded with a AVANCEDRX400 NMR spectrometer (Bruker, Germany) operated at 400/600 MHz. Electrospray ionization mass spectra were obtained with a High Performance 1100 Liquid Chromatography-Mass Spectrometer (Agilent Technologies, USA). The morphology and size of aggregates were characterized with Scanning Electron Microscopy (SEM) (Quanta, FEI) and a JEM 2100 high resolution transmission electron microscope (HRTEM, JEOL, Japan).

\subsection{Synthesis}

The synthetic strategies adopted are outlined in Scheme 1.

2.3.1 Compound 1 (1,1,2,2-tetra-p-tolylethene). Compound 1 was synthesized as previously reported. ${ }^{58}$ Zinc powder $(1.0 \mathrm{~g}$, $15.3 \mathrm{mmol}$ ) was added into a $100 \mathrm{~mL}$ double-neck flask. Under an $\mathrm{N}_{2}$ atmosphere, $25 \mathrm{~mL}$ anhydrous THF was added, cooled to

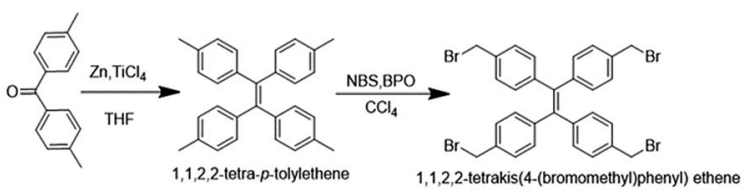

[1]

[2]

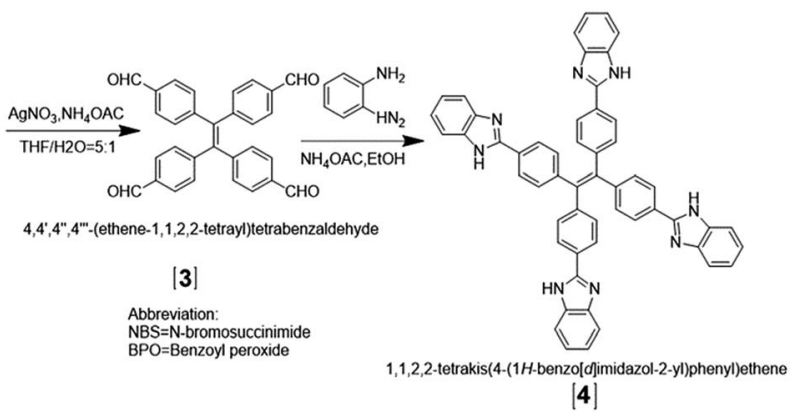

Scheme 1 Synthetic route to new 1,1,2,2-tetrakis(4-(1H-benzo[d] imidazole-2-yl)phenyl)ethene molecules, TBI-TPE.
$-5{ }^{\circ} \mathrm{C}$, and then $\mathrm{TiCl}_{4}(1.1 \mathrm{~mL}, 10 \mathrm{mmol})$ and pyridine $(0.05 \mathrm{~mL}$, $0.6 \mathrm{mmol}$ ) were added dropwise. The mixture was refluxed at $75{ }^{\circ} \mathrm{C}$ for $2 \mathrm{~h}$ and $20 \mathrm{~mL}$ THF solution of 4,4'-dimethylbenzophenone (1.05 g, $5 \mathrm{mmol}$ ) was added. The solution was further refluxed at $75{ }^{\circ} \mathrm{C}$ for $12 \mathrm{~h}$. Upon completion of the reaction, the solution was cooled to room temperature and poured into a $40 \mathrm{~mL} 30 \%$ water solution of $\mathrm{K}_{2} \mathrm{CO}_{3}$, which was stirred for $5 \mathrm{~min}$ and then filtered. The filtrate was extracted with ethyl acetate, successively washed with water, brine, and dried with $\mathrm{Na}_{2} \mathrm{SO}_{4}$. A light-yellow solid was obtained by rotary evaporation, and purified by column chromatography (silica gel, petroleum ether) to result in a white product 1 (yield, 85\%). The ${ }^{1} \mathrm{H}$ NMR and ${ }^{13} \mathrm{C}$ NMR spectra of product $1\left(400 \mathrm{MHz}, \mathrm{CDCl}_{3}, 25{ }^{\circ} \mathrm{C}\right.$ ), $\delta$ (TMS, ppm) are shown in Fig. $\mathrm{S} 1$ and $\mathrm{S} 2, \uparrow$ respectively. High resolution MS of product 1 is shown in Fig. $\mathrm{S} 3, \dagger(\mathrm{m} / \mathrm{z})$ : calculated for $\mathrm{C}_{30} \mathrm{H}_{28}[\mathrm{M}+\mathrm{H}]^{+}$389.2225, found 389.2228, $[\mathrm{M}+\mathrm{Na}]^{+}$ 411.2083, found 411.2080, $[\mathrm{M}+\mathrm{K}]^{+} 427.1822$, found 427.1825 (high resolution).

2.3.2 Compound 2 (1,1,2,2-tetrakis(4-(bromomethyl) phenyl)-ethene). 1,1,2,2-Tetra- $p$-tolylethene $770 \mathrm{mg}$ (2 mmol) obtained in the previous step was added into a $100 \mathrm{~mL}$ round bottom flask, and then NBS (1424 mg, $8 \mathrm{mmol}$ ), BPO (64 mg) and $\mathrm{CCl}_{4}(30 \mathrm{~mL})$ were added. Under an $\mathrm{N}_{2}$ atmosphere, the mixture reacted at $80{ }^{\circ} \mathrm{C}$ for $2 \mathrm{~h}$. Then, adding in NBS $(1424 \mathrm{mg}$, $8 \mathrm{mmol}$ ) and BPO (64 mg), the mixture reacted at $80{ }^{\circ} \mathrm{C}$ for a further $2 \mathrm{~h}$. After $2 \mathrm{~h}$, NBS (1424 mg, $8 \mathrm{mmol}$ ), and BPO (64 $\mathrm{mg}$ ) were added, and the mixture was left for $24 \mathrm{~h}$. It was then filtered quickly while the solution was hot, and the solid was washed with ethyl acetate, and the filtrate collected. The organic phase is obtained by rotary evaporation of the yellow solid, without further purification we then proceeded directly to the next step.

2.3.3 Compound $3\left(4,4^{\prime}, 4^{\prime \prime}, 4^{\prime \prime \prime}\right.$-(ethene-1,1,2,2-tetrayl)tetrabenzaldehyde). The solid from the previous step $(2.0 \mathrm{~g})$, sodium acetate trihydrate $(1500 \mathrm{mg}, 18 \mathrm{mmol})$, silver nitrate $(3400 \mathrm{mg}$, $20 \mathrm{mmol})$, THF $(25 \mathrm{~mL})$ and $\mathrm{H}_{2} \mathrm{O}(5 \mathrm{~mL})$ were mixed and further refluxed at $75{ }^{\circ} \mathrm{C}$ for $24 \mathrm{~h}$, the solution was cooled to room temperature and filtered. The filtrate was extracted with ethyl acetate, washed successively with water, brine, and dried with $\mathrm{Na}_{2} \mathrm{SO}_{4}$. A light yellow viscous liquid was obtained by rotary evaporation, and purified by column chromatography (silica gel, petroleum ether/ethyl acetate $=5: 1$ ) to result in a yellowgreen product 3 (yield: 25\%)..$^{59-61}{ }^{1} \mathrm{H}$ NMR and ${ }^{13} \mathrm{C}$ NMR spectra of product $3\left(400 \mathrm{MHz}, \mathrm{CDCl}_{3}, 25^{\circ} \mathrm{C}\right), \delta(\mathrm{TMS}, \mathrm{ppm})$ are shown in Fig. $\mathrm{S} 4$ and $\mathrm{S} 5, \dagger$ respectively. As shown in Fig. S6, $\dagger$ high resolution MS $(\mathrm{m} / \mathrm{z})$ of product 3: calculated for $\mathrm{C}_{30} \mathrm{H}_{20} \mathrm{O}_{4}$ $[\mathrm{M}+\mathrm{H}]^{+}$445.1434, found 445.1433, $[\mathrm{M}+\mathrm{Na}]^{+}$467.1253, found 467.1259 (high resolution).

2.3.4 Compound $4 \quad(1,1,2,2$-tetrakis $(4-(1 H$-benzo $[d]$ imidazol-2-yl)phenyl)ethene) TBI-TPE. $\quad 4,4^{\prime}, 4^{\prime \prime}, 4^{\prime \prime \prime}$-(Ethene1,1,2,2-tetrayl)tetrabenzaldehyde (46 mg, $0.1 \mathrm{mmol}$ ), 1,2-diaminobenzene (130 mg, $1.2 \mathrm{mmol}$ ), ammonium acetate (92 mg, $1.2 \mathrm{mmol})$, EtOH $(2 \mathrm{~mL})$ were further refluxed at $75{ }^{\circ} \mathrm{C}$ for $5 \mathrm{~h}$. The precipitate was collected by centrifugation and washed with ethanol. The product was dried in vacuum at $60{ }^{\circ} \mathrm{C}$ overnight to give a yellow solid (yield, 70\%). ${ }^{61-64}{ }^{1} \mathrm{H}$ NMR and ${ }^{13} \mathrm{C}$ NMR spectra (600 MHz, DMSO- $\left.d_{6}, 25^{\circ} \mathrm{C}\right), \delta$ (TMS, ppm) of compound 
4 are shown in Fig. S7 and $S 8, \dagger$ respectively. As shown in Fig. S9, $\uparrow$ high resolution MS $(\mathrm{m} / \mathrm{z})$ of compound 4: calculated for $\mathrm{C}_{54} \mathrm{H}_{36} \mathrm{~N}_{8}[\mathrm{M}+2 \mathrm{H}]^{2+} 399.1612$, found 399.1604 (high resolution).

\subsection{Analysis of real sample}

A waste liquor sample was taken from a factory in Kunming city. The sample was filtered through a $0.22 \mu \mathrm{m}$ membrane (Millipore) prior to detection. One hundred microliters of the above waste sample was added to $900 \mu \mathrm{L}$ of methyl alcohol solution containing TBI-TPE $(2 \mu \mathrm{M})$ and then analyzed using the developed detection method.

\section{Results and discussion}

\subsection{Design and synthesis of $(1,1,2,2$-tetrakis $(4-(1 H$-benzo $[d]$} imidazol-2-yl)phenyl)ethene) TBI-TPE

The four-step synthesis adopted for preparing TBI-TPE is shown in Scheme 1. Compound 1 (1,1,2,2-tetra- $p$-tolylethene) was prepared from 4,4'-dimethylbenzophenone by McMurry coupling. Compound 2 was obtained by NBS under the induction of a free radical initiator (BPO) in $\mathrm{CCl}_{4}$ at $80{ }^{\circ} \mathrm{C}$. Compound 2 is oxidized to compound 3 using silver as the catalyst. TBI-TPE is produced by refluxing 3 at $75^{\circ} \mathrm{C}$.

To verify the results of our synthesis, these compounds were checked by NMR and MS (Fig. S1-S9†).

\subsection{AIE properties}

After structure confirmation, the AIE properties of TBI-TPE were investigated. To further illustrate the AIE feature, the study of the emission characteristics of TBI-TPE in mixtures of $\mathrm{CH}_{3} \mathrm{OH}$ and water with different water fractions was conducted. As shown in Fig. 1 and S10, $\dagger$ the fluorescence of TBI-TPE is a yellowish green emission at $525 \mathrm{~nm}$ and is strongest at $f_{\mathrm{w}}=$
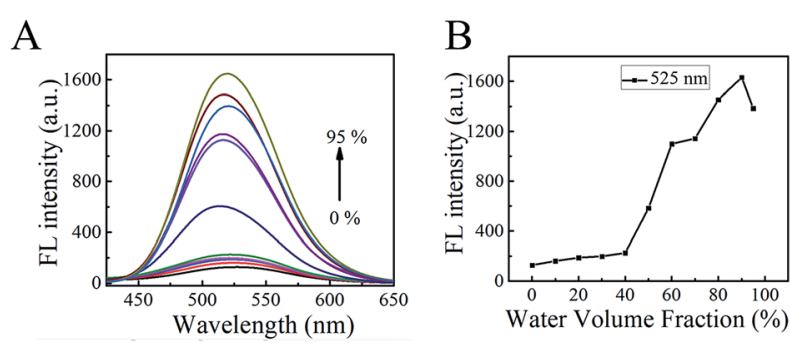

C

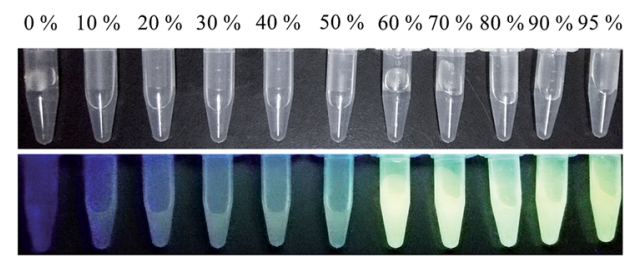

Fig. 1 (A) Fluorescence intensity spectra. (B) Plots of fluorescence intensity versus water fraction of TBI-TPE in mixtures of $\mathrm{CH}_{3} \mathrm{OH}$ /water with different water fractions (from 0 to 95\%). (C) Images of TBI-TPE in $\mathrm{CH}_{3} \mathrm{OH}$ with the increasing water fraction taken under daily light (top), and UV light illumination (bottom) ( $\lambda_{\mathrm{ex}}=365 \mathrm{~nm}$ ). TBI-TPE concentration $=10 \mu \mathrm{M}, E_{\mathrm{x}}=335 \mathrm{~nm}$.
$90 \%$, which is 13 times stronger than the one at $f_{\mathrm{w}}=0 \%$. The compound is almost non-emissive when it is dissolved in pure organic solution $\left(f_{\mathrm{w}}=0 \%\right)$ and it gradually becomes emissive as water is added, proving its prominent AIE activity. The increase in fluorescence intensity indicated TBI-TPE tended to aggregate when the $f_{\mathrm{w}}$ value increased. Upon aggregation, the free intramolecular rotations of the excited molecules are restricted. This blocks the non-radiative relaxation pathway and favors the radiative decay.

\subsection{Silver ion sensing studies}

3.3.1 The action and mechanism of TBI-TPE and $\mathbf{A g}^{+}$. To examine the fluorescence response of TBI-TPE towards $\mathrm{Ag}^{+}$, we added $\mathrm{Ag}^{+}$into a $\mathrm{CH}_{3} \mathrm{OH}$ solution of TBI-TPE. As shown in Fig. $2 \mathrm{~A}, \mathrm{~S} 11, \dagger$ the fluorescence spectra indicated that the addition of $\mathrm{Ag}^{+}$obviously increased the fluorescence intensity of composites at $525 \mathrm{~nm}$ (Fig. 2A, S11 $\dagger$ ). Whereas, the UV absorption spectra of TBI-TPE in $\mathrm{CH}_{3} \mathrm{OH}$ in the presence of $\mathrm{Ag}^{+}$ did not change (Fig. 2B).

In Fig. 3A the Tyndall effect can be observed in a Ag-TBI-TPE solution by laser irradiation, indicating the formation of aggregates. The formation of Ag-TBI-TPE aggregates was further confirmed by HRTEM and SEM measurements (Fig. 3B, $\mathrm{S} 12 \dagger)$. Nanoparticles with diameter of $20 \mathrm{~nm}$ were observed in these images. The above results reveal that aggregates of $\mathrm{Ag}-$ TBI-TPE were formed in $\mathrm{CH}_{3} \mathrm{OH}$ solution, resulting in enhanced fluorescence, which is similar to the AIE mechanism of assay.

Next, we studied the stoichiometric coordination of TBI-TPE with $\mathrm{Ag}^{+}$. As shown in Fig. 3C, Job's plot established that the stoichiometry ratio of the TBI-TPE and $\mathrm{Ag}^{+}$strongly fluorescent complex is $1: 2$. Furthermore, the mass of Ag-TBI-TPE complex was determined using MALDI-TOF MS. A peak at 2021.398 was obtained (Fig. 4A), suggesting the Ag-TBI-TPE complex formed is (TBI-TPE) ${ }_{2} \mathrm{Ag}_{4}$, which corresponds to the theoretical calculation (2021.312, Fig. 4B). These results are consistent with the Job's plot. According to these results, we speculate that the $\mathrm{N}$ atoms of imidazole are good electron donors, which display good ability to coordinate positive $\mathrm{Ag}^{+}$, forming a stable and strong fluorescent complex. The schematic diagram of this phenomenon is shown in Fig. 3D.

Furthermore, it is well known that $\mathrm{pH}$ changes according to the concentration of $\mathrm{Ag}^{+}$, which will greatly effect the interaction between $\mathrm{Ag}^{+}$and the probe. The effect of $\mathrm{pH}$ on the
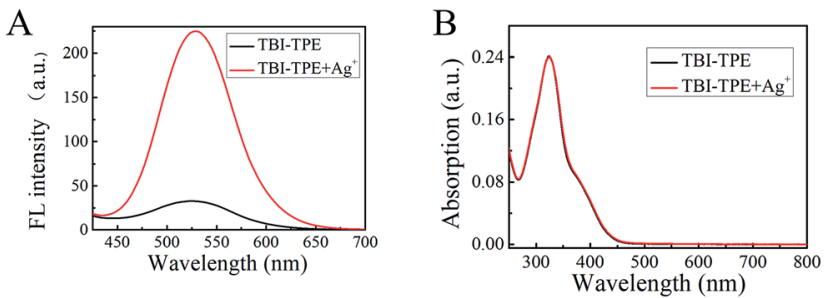

Fig. 2 (A) Fluorescence spectra. (B) UV absorption spectra of TBI-TPE $(4 \mu \mathrm{M})$ in $\mathrm{CH}_{3} \mathrm{OH}$ in the presence of $\mathrm{Ag}^{+}(4 \mu \mathrm{M}), E_{\mathrm{x}}=370 \mathrm{~nm}$. 


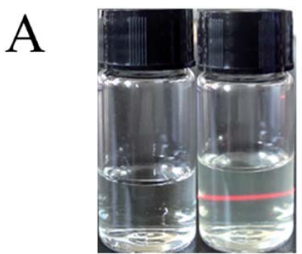

$\mathrm{C}$

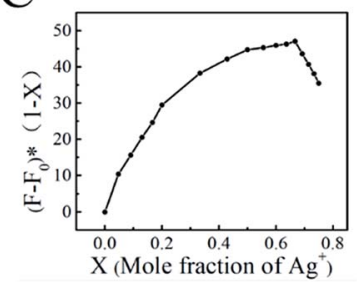

D

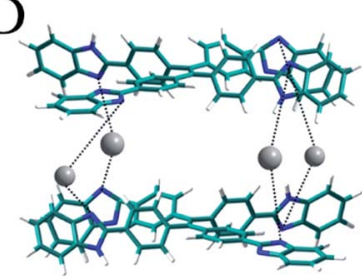

Fig. 3 (A) Photographs of TBI-TPE $(100 \mu \mathrm{M})$ in $\mathrm{CH}_{3} \mathrm{OH}$ exposed to daylight (left), and TBI-TPE in the presence of $\mathrm{Ag}^{+}(300 \mu \mathrm{M})$ exposed to a laser pen (right). (B) TEM image of the aggregates. (C) Job's plot showing $1: 2$ binding of TBI-TPE with $\mathrm{Ag}^{+}$. (D) Illustration of the selfassembly aggregation.
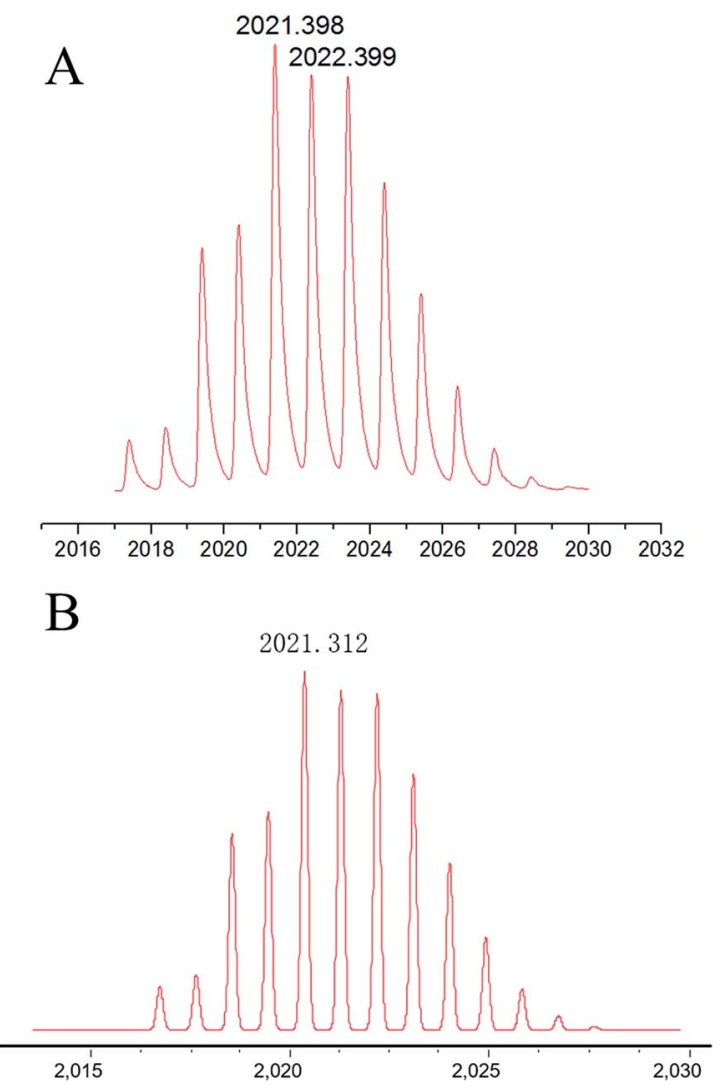

Fig. 4 Experimental (A), and calculated (B), MALDI-TOF of the AgTBI-TPE complex.

interaction between $\mathrm{Ag}^{+}$and the probe were investigated by fluorescence measurement. As shown in Fig. S13, $\dagger$ the fluorescence intensity at $525 \mathrm{~nm}$ increased with increasing $\mathrm{pH}$ from 4.0 to 7.0 , and the fluorescence signal decreased with increasing $\mathrm{pH}$ value. This tendency revealed that the interaction between the

probe and $\mathrm{Ag}^{+}$would be effected by the deprotonation process. The best fluorescent performance of $\mathrm{Ag}-\mathrm{TBI}-\mathrm{TPE}$ at neutral $\mathrm{pH}$ is beneficial for the detection of $\mathrm{Ag}^{+}$in environmental samples.

3.3.2 Selectivity of assay. The $\mathrm{N}$ atoms of the imidazole moiety have a unique chelating ability to transition metal ions. So to verify the fluorescence response of TBI-TPE towards other metal ions, we examined the emission characteristics of TBITPE in the presence of various metal ions in $\mathrm{CH}_{3} \mathrm{OH}$ solution. As shown in the inset of Fig. S14, $\dagger$ the fluorescence emission of TBI-TPE in the presence of other metal ions is weak. The corresponding fluorescence spectra (Fig. 5A) indicates that the addition of other metal ions $\left(\mathrm{Cu}^{2+}, \mathrm{Ca}^{2+}, \mathrm{Cd}^{2+}, \mathrm{Co}^{2+}, \mathrm{Cr}^{2+}, \mathrm{Mg}^{2+}\right.$, $\mathrm{Er}^{3+}, \mathrm{Eu}^{3+}, \mathrm{Fe}^{2+}, \mathrm{Fe}^{3+}, \mathrm{K}^{+}, \mathrm{Zn}^{2+}, \mathrm{Na}^{+}, \mathrm{Ni}^{2+}, \mathrm{Pd}^{2+}, \mathrm{Sn}^{2+}, \mathrm{Tb}^{3+}$ and $\mathrm{Zr}^{4+}$ ) into TBI-TPE solution causes no change, weak fluorescence is retained. This result indicates that the fluorescence response of TBI-TPE is highly selective towards $\mathrm{Ag}^{+}$over other metal ions.

3.3.3 Response time. Fig. 5B depicts the typical timedependent fluorescent spectra of the $\mathrm{CH}_{3} \mathrm{OH}$ solution containing TBI-TPE after the addition of $\mathrm{Ag}^{+}$into the TBI-TPE solution.
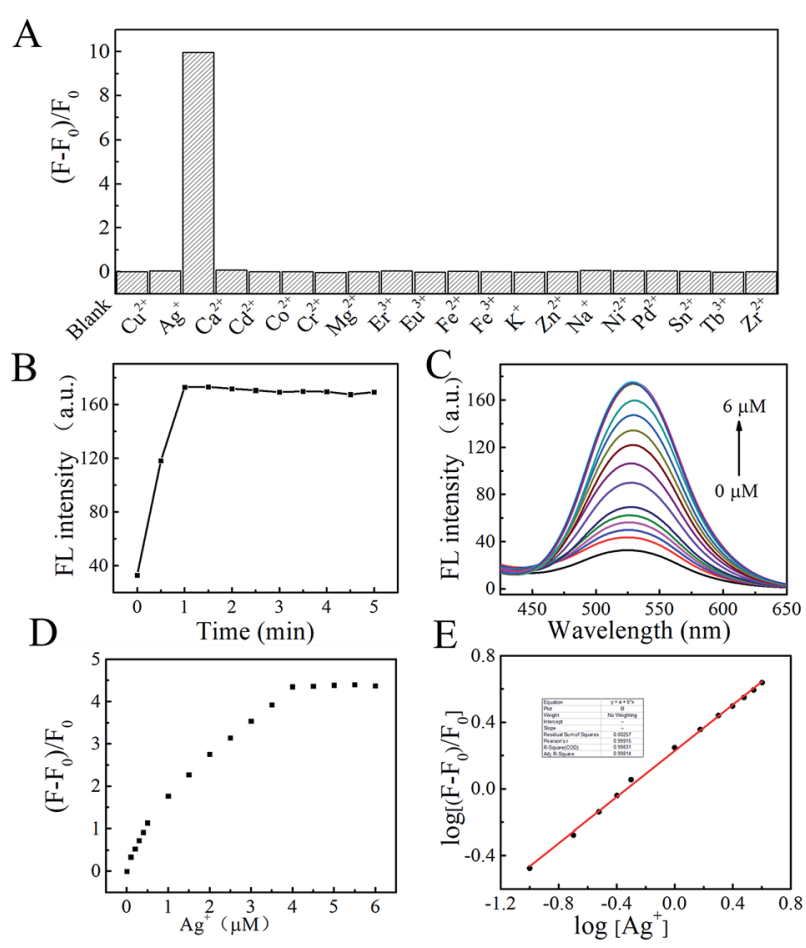

Fig. 5 (A) Bars denote the fluorescence intensity difference $\left(F-F_{0}\right) / F_{0}$ in the presence of a series of metal ions. $F_{0}$ is the fluorescence intensity of TBI-TPE $(10 \mu \mathrm{M})$ only, and $F$ is the fluorescence intensity of TBI-TPE in the presence of metal ions $(20 \mu \mathrm{M})$. (B) Time-dependent fluorescence response of the $2 \mu \mathrm{M} \mathrm{TBI-TPE}$ to $4 \mu \mathrm{M} \mathrm{Ag}{ }^{+}$in $\mathrm{CH}_{3} \mathrm{OH}$. (C) Fluorescence spectra of TBI-TPE $(2 \mu \mathrm{M})$ in $\mathrm{CH}_{3} \mathrm{OH}$ in the presence of increasing concentrations of $\mathrm{Ag}^{+}$(from 0 to $6 \mu \mathrm{M}$ ); $E_{\mathrm{x}}=370 \mathrm{~nm}$. (D) Variation of the fluorescence intensity at $525 \mathrm{~nm}$ of TBI-TPE with a gradual increase in the concentration of $\mathrm{Ag}^{+}$. (E) Variation of the intensity ratio of TBI-TPE $(2 \mu \mathrm{M})$ with an increase in the concentration of $\mathrm{Ag}^{+}$for the determination of the detection limit, where $F_{0}$ is the intensity at $525 \mathrm{~nm}$ when the metal ion concentration is 0 , and $F$ is the intensity at each metal ion concentration tested during titration. $E_{\mathrm{x}}=$ $370 \mathrm{~nm}$. 
Upon addition of $\mathrm{Ag}^{+}$, the fluorescent spectrum of TBI-TPE was recorded immediately and then every $30 \mathrm{~s}$. The fluorescent intensity of TBI-TPE was increased significantly and reached a plateau after $1 \mathrm{~min}$. Hence, this result indicates that TBI-TPE can serve as a fluorescent chemical probe for the detection of $\mathrm{Ag}^{+}$with fast response.

3.3.4 Sensitivity of assay. The fluorescence response of TBI-TPE to $\mathrm{Ag}^{+}$at different concentrations is shown in Fig. 5C and $\mathrm{D}$. The fluorescence at $525 \mathrm{~nm}$ was increased gradually as $\mathrm{Ag}^{+}$concentration increased 0 to $4 \mu \mathrm{M}$. When the concentration reaches $4 \mu \mathrm{M}$, the intensity of fluorescence remains constant. This indicates that TBI-TPE has a certain coordination relationship with $\mathrm{Ag}^{+}$when the fluorescence intensity reaches a certain value and then reaches a plateau. Titration studies with TBI-TPE revealed good linearity between increasing level $\log \left[\left(F-F_{0}\right) / F_{0}\right]$ and $\log \left[\mathrm{Ag}^{+}\right]$in the range from 0.1 to $4 \mu \mathrm{M}$ (Fig. 5E) where, $F_{0}$ is the fluorescence intensity of TBI-TPE (2 $\mu \mathrm{M}$ ) only, and $F$ is the fluorescence intensity of TBI-TPE in the presence of metal ions. The detection limit is $90 \mathrm{nM}$ on the basis of a signal-to-noise ratio of $3: 1$.

\subsection{Sample application}

The practicability of TBI-TPE fluorescent probe was assessed by applying it to the analysis of $\mathrm{Ag}^{+}$in waste liquor samples, provided by a factory in Kunming city. An average value of 0.112 $\pm 0.003 \mu \mathrm{M} \mathrm{Ag}^{+}$was found for $n=3$ determinations using our developed approach with good recovery (99 $\pm 2 \%$ ), after subtraction of the intercept from the standard calibration curve (Fig. 5E), which is consistent with the ICP-MS measurement, $0.113 \pm 0.008 \mu \mathrm{M}$. These results suggest that our fluorescence probe can be used for $\mathrm{Ag}^{+}$determination in environmental samples.

\section{Conclusions}

In conclusion, we have designed and synthesized an AIE fluorescence probe containing benzimidazole group, which exhibited highly sensitive and selective "turn-on" fluorescence for the determination of $\mathrm{Ag}^{+}$with a detection limit of $0.090 \mu \mathrm{M}$. The stoichiometry of TBI-TPE and $\mathrm{Ag}^{+}$in the complex was established to be $1: 2$ using Job's plot and MS studies. Thanks to the unique AIE property of TPE, a facile strategy for the construction of high performance "signal on" fluorescent probes has been presented and could be developed for other potential applications.

\section{Conflicts of interest}

There are no conflicts to declare.

\section{Acknowledgements}

This work was financially supported by the National Natural Science Foundation of China (NSFC, 21765024).

\section{Notes and references}

1 T. W. Purcell and J. J. Peters, Environ. Toxicol. Chem., 1998, 17(4), 539-546.

2 M. Alvarez-Corral, M. Munoz-Dorado and I. RodriguezGarcia, Chem. Rev., 2008, 108(8), 3174-3198.

3 J. L. Barriada, A. D. Tappin, E. H. Evans and E. P. Achterberg, TrAC, Trends Anal. Chem., 2007, 26(8), 809-817.

4 P. L. Drake and K. J. Hazelwood, Ann. Occup. Hyg., 2005, 49(7), 575-585.

5 X. B. Zhang, Z. X. Han, Z. H. Fang, G. L. Shen and R. Q. Yu, Anal. Chim. Acta, 2006, 562(2), 210-215.

6 H. H. Harris, I. J. Pickering and G. N. George, Science, 2003, 301(5637), 1203.

7 D. Maity and T. Govindaraju, Chem. Commun., 2012, 48(7), 1039-1041.

8 S. Goswami, A. K. Das and S. Maity, Dalton Trans., 2013, 42(46), 16259-16263.

9 S. Pal, Y. K. Tak and J. M. Song, Appl. Environ. Microbiol., 2007, 73(6), 1712-1720.

10 C. Marambio-Jones and E. M. V. Hoek, J. Nanopart. Res., 2010, 12(5), 1531-1551.

11 P. C. Lee and D. Meisel, J. Phys. Chem., 1982, 86, 3391-3395.

12 I. Sondi and B. Salopek-Sondi, J. Colloid Interface Sci., 2004, 275(1), 177-182.

13 H. Blum, H. Beier and H. J. Gross, Electrophoresis, 1987, 8(2), 93-99.

14 S. C. K. Shum, H. M. Pang and R. S. Houk, Anal. Chem., 1992, 64(20), 2444-2450.

15 L. G. Martin, L. T. Jongwana and A. M. Crouch, Electrochim. Acta, 2010, 55(14), 4303-4308.

16 C. P. Hanna, J. F. Tyson and S. McIntosh, Anal. Chem., 1993, 65(5), 653-656.

17 Y. Yu, Q. Zhang, C. C. Chang, Y. Liu, Z. Yang, Y. Guo and M. Rafailovich, Analyst, 2016, 141(19), 5607-5617.

18 Y. Yu, Q. Zhang, J. Buscaglia, C. C. Chang, Y. Liu, Z. Yang and M. Rafailovich, Analyst, 2016, 141(14), 4424-4431.

19 Y. Chang, Z. Zhang, J. Hao, W. Yang and J. Tang, Sens. Actuators, B, 2016, 232, 692-697.

20 Z. Yan, Q. Zhao, M. Wen, L. Hu, X. Zhang and J. You, Spectrochim. Acta, Part A, 2017, 186, 17-22.

21 W. Shi, Y. Chen, X. Chen, Z. Xie and Y. Hui, J. Lumin., 2016, 174, 56-62.

22 W. Shen, L. Wang, M. Wu, et al., Inorg. Chem. Commun., 2016, 70, 107-110.

23 S. Y. Lee, K. H. Bok and C. Kim, RSC Adv., 2017, 7(1), 290299.

24 L. Tang and M. Cai, Sens. Actuators, B, 2012, 173, 862-867.

25 R. C. Duckworth, J. M. Pfotenhauer, J. W. Lue, et al., AIP Conf. Proc., 2002, 613(1), 449-456.

26 J. R. Lakowicz, J. Malicka, S. D’Auria and I. Gryczynski, Anal. Biochem., 2003, 320(1), 13-20.

27 Z. Xu, S. J. Han, C. Lee, J. Yoon and D. R. Spring, Chem. Commun., 2010, 46(10), 1679-1681.

28 H. C. Hung, C. W. Cheng, Y. Y. Wang, et al., Eur. J. Org. Chem., 2009, 2009(36), 6360-6366. 
29 L. Prodi, F. Bolletta, M. Montalti, et al., Coord. Chem. Rev., 2000, 205(1), 59-83.

30 J. Fan, C. Chen, Q. Lin, et al., Sens. Actuators, B, 2012, 173, 874-881.

31 Y. Hong, J. W. Y. Lam and B. Z. Tang, Chem. Soc. Rev., 2011, 40(11), 5361-5388.

32 Y. Hong, J. W. Y. Lam and B. Z. Tang, Chem. Commun., 2009, 29, 4332-4353.

33 J. Luo, Z. Xie, J. W. Y. Lam, et al., Chem. Commun., 2001, 18, 1740-1741.

34 M. Wang, G. Zhang, D. Zhang, et al., J. Mater. Chem., 2010, 20(10), 1858-1867.

35 Y. Hong, M. Häußler, J. W. Y. Lam, et al., Chem.-Eur. J., 2008, 14(21), 6428-6437.

36 H. Shi, R. T. K. Kwok, J. Liu, et al., J. Am. Chem. Soc., 2012, 134(43), 17972-17981.

37 Y. Liu, Y. Tang, N. N. Barashkov, et al., J. Am. Chem. Soc., 2010, 132(40), 13951-13953.

38 Y. Liu, C. Deng, L. Tang, A. Qin, R. Hu, J. Z. Sun and B. Z. Tang, J. Am. Chem. Soc., 2011, 133(4), 660-663.

39 H. Shi, J. Liu, J. Geng, et al., J. Am. Chem. Soc., 2012, 134(23), 9569-9572.

40 K. Hatano, H. Saeki, H. Yokota, et al., Tetrahedron Lett., 2009, 50(42), 5816-5819.

41 W. Qin, D. Ding, J. Liu, et al., Adv. Funct. Mater., 2012, 22(4), 771-779.

42 Q. Zhao, K. Li, S. Chen, et al., J. Mater. Chem., 2012, 22(30), 15128-15135.

43 Y. Liu, S. Chen, J. W. Y. Lam, et al., Chem. Mater., 2011, 23(10), 2536-2544.

44 J. P. Xu, Y. Fang, Z. G. Song, et al., Analyst, 2011, 136(11), 2315-2321.

45 M. Zhao, M. Wang, H. Liu, et al., Langmuir, 2008, 25(2), 676678.

46 M. Wang, X. Gu, G. Zhang, et al., Anal. Chem., 2009, 81(11), 4444-4449.
47 R. Misra, T. Jadhav, B. Dhokale, et al., Chem. Commun., 2014, 50(65), 9076-9078.

48 Z. Zhao, S. Chen, X. Shen, et al., Chem. Commun., 2010, 46(5), 686-688.

49 Z. Zhao, P. Lu, J. W. Y. Lam, et al., Chem. Sci., 2011, 2(4), 672675.

50 Y. Dong, J. W. Y. Lam, A. Qin, et al., Appl. Phys. Lett., 2007, 91(1), 011111.

51 H. Lu, Y. Zheng, X. Zhao, et al., Angew. Chem., Int. Ed., 2016, 55(1), 155-159.

52 U. Kalinowska-Lis, A. Felczak, L. Chęcińska, et al., J. Organomet. Chem., 2014, 749, 394-399.

53 J. C. Geng, L. Qin, X. Du, et al., Z. Anorg. Allg. Chem., 2012, 638(7-8), 1233-1238.

54 J. H. M. Hill, J. Organomet. Chem., 1963, 28(7), 1931-1932.

55 C. K. Xia, C. Z. Lu, Q. Z. Zhang, et al., Cryst. Growth Des., 2005, 5(4), 1569-1574.

56 H. Wu, J. Yuan, Y. Bai, et al., Dalton Trans., 2012, 41(29), 8829-8838.

57 M. Liu, A. Kira and H. Nakahara, Langmuir, 1997, 13(18), 4807-4809.

58 J. Dessingou, A. Mitra, K. Tabbasum, et al., J. Org. Chem., 2011, 77(1), 371-378.

59 T. S. Navale, K. Thakur and R. Rathore, Org. Lett., 2011, 13(7), 1634-1637.

60 O. Dann, G. Bergen, E. Demant, et al., Eur. J. Inorg. Chem., 1971, 749(1), 68-89.

61 G. J. Liu, Z. Long, H. J. Lv, C. Y. Li and G. W. Xing, Chem. Commun., 2016, 52(67), 10233-10236.

62 Y. X. Zhu, Z. W. Wei, M. Pan, H. P. Wang, J. Y. Zhang and C. Y. Su, Dalton Trans., 2016, 45(3), 943-950.

63 Y. R. Girish, K. S. Sharath Kumar, K. N. Thimmaiah, K. S. Rangappa and S. Shashikanth, RSC Adv., 2015, 5(92), 75533-75546.

64 H. Sharghi, O. Asemani and R. Khalifeh, Synth. Commun., 2008, 38(7), 1128-1136. 